\title{
Reflection on Shilin Yi Nationality Bimo Culture and Culture Reproduction
}

\author{
Zhao Ying \\ Southwest Minzu University, Southwest Institute for Nationalities, China
}

Keywords: Shilin Yi nationality; Bimo culture; Culture reproduction

\begin{abstract}
Since ancient times, Bimo has been active on stage in Chinese history as an inheritor of culture. As a pattern of manifestation of intangible cultural heritage, Bimo inheritors have become an important carrier of the Yi culture and art. In today's social context, Bimo has undergone unprecedented changes, and the phenomenon of cultural reproduction occurred. Cultural reproduction has exerted a profound influence on the protection and inheritance of traditional national culture. The study of changes and reproduction of Yi Nationality Bimo Culture not only concerns the protection and inheritance of intangible cultural heritage, but also promotes the development and prosperity of Yi culture.
\end{abstract}

\section{Introduction}

Yi nationality is the earliest aboriginal of Shilin Yi Autonomous County, which has a long history and culture of great splendor. The nationality had set up powerful tribes in Sui and Tang dynasties. With the collapse of the native chieftain system in the Ming Dynasty and the increase of immigrants, the assimilation and integration between Yi nationality and nonnative ethnic minorities were increasing and the internal differentiation was also prominent, to the extent that Yi branches were formed in Qing Dynasty, such as Sani, Black Yi, Bai Yi and Yi Qin. Meanwhile, the living pattern of Yi nationality changed, most of the population migrated to the mountainous area, and a few of them were scattered in the barrage area and lived with the Han nationality together. Bimo culture is a classic complex of various types of witchcrafts and Yi characters. The gist of the culture was the belief of souls or ghosts and gods in earlier times, namely, for all the major and minor issues, what Bimo people did was to seek help from a wizard or use a chicken bone to take auspices" [1]. With the development of modern society, the folk beliefs and other national psychology contained in the Bimo culture gradually faded away. As a traditional national culture in villages, Bimo culture is facing survival crisis, but as a symbolic culture of the Yi nationality, it is still rooted in the heart of the public. In the face of social and cultural changes, Bimo culture did not blindly retreat from social life, but integrated into modern social culture with a "regenerative" form to produce new cultural connotations. This kind of cultural reproduction is mainly manifested in that people take the traditional Bimo culture as the prototype and recombine the inner elements of the culture, so as to make it glow with new vitality and adapt to the current social and cultural development. The reproductive state of the Yi nationality's Bimo culture should be implemented into the specific rural society and compatriot psychology, so as to realize the re-identification and re-localization of the culture. This paper attempts to analyze the promoting factors and explore the protection and inheritance of Bimo culture as an intangible cultural heritage by focusing on the changes and reproduction of the culture, hoping to promote the development and prosperity of $\mathrm{Yi}$ culture.

\section{Bimo culture reproduction}

Cultural change is an important law of the development of human society and culture, and the relative stability of culture is temporary. Bimo culture is an important content of the development of Yi culture and has relative stability and absolute variability. As to relative stability, to be more 
specific, Bimo culture has been permanently fixed with the way of life and means of livelihood and became an indispensable part of people's daily life. In other words, the stability of Bimo culture will become stronger as long as the society is stable and people's way of life and means of livelihood have no radical change. Since the reform and opening, with the rapid development of social economy and culture, cultural reproduction has become an important matter of cultural changes. Bourdieu mentioned in his book Reproduction in Education, Society and Culture that, "this theory is used to analyze how the capitalist cultural system created the consciousness of safeguarding the existing social system in people's minds, so that the existing social structure and power relations can be maintained, namely, being reproduced" [2]. Cultural development is a process containing continuous development and reproduction. Humans bring forth the new through the old in culture by accommodation, reproduction and creation, so as not to be phased out, and social continuation has been maintained through cultural reproduction. In other words, cultural reproduction has become a survival strategy for human culture. Bourdieu also stressed that "cultural studies should focus more on the culture reproduction activities, rather than rest on the generated cultural products, and the studies on culture reproduction process should be promoted to the theoretical level of studies on human general practice" [3]. Based on this idea, according to the specific situation of Shilin Yi society, this paper uses Bourdieu's theory of cultural reproduction to carry out discussion from three aspects of Bimo culture as a "symbol", Bimo culture as "cultural tourism resource" and Bimo culture as "intangible cultural heritage".

Bimo culture as a "symbol". With the development of society, Bimo culture has undergone great changes and the phenomenon of cultural reproduction appeared, which is mainly expressed by the religious buddhist musical apparatus, clothing, painting, sacred classics, sculpture and paper cutting of Bimo and Suni. This means that Bimo culture has appeared in the ethnic culture of the Yi nationality with the identity of a cultural symbol. Taking Bimo painting as an example, in the traditional sense, Bimo painting is a kind of disposable art, and most of the ghost boards or woodcuts will be abandoned after the religious rites. However, with the change of the national psychology and folk methods of beliefs, Bimo painting appears as a cultural symbol in various scenes such as painting products, architectural decorations and tourist commodities. As one of the materialized forms of Bimo culture, Bimo painting is an organic component of Bimo culture. Bimo culture as a "symbol" is a process in which the specimen of painting is extracted from daily life of the masses and used as a cultural symbol to carry out reproduction and innovation, namely, a process in which culture reproduction is shaped like a specimen.

Bimo culture as a "symbol" is not baseless, and it cannot be separated from the promotion and planning by official oriented social elite class. The process of elite class's extraction, concentration, abstraction, packaging and promotion of traditional Bimo culture is the cultural reproduction of traditional ethnic culture. Bimo culture reproduction is conducive to strengthening national coherence, building socialist political civilization, enhancing national cultural identity, carrying forward the spirit and legacy of Yi nationality, maintaining social stability and achieving social control.

Bimo culture as cultural tourism resource. Nowadays, in the economic development of regions inhabited by ethnic groups, tourism development has become an indispensable part. Local governments are positively planning to develop and utilize the local cultural tourism resources. The tourist industry in Shilin Yi Autonomous County is one of the pillar industries in the area. In the context of the development of local tourism and cultural resources, Bimo culture has become a new resource for local government and main market players, transforming the traditional customs that merely survive in the hearts of the masses into the phenomenon of Bimo cultural performances. Bimo cultural performances, namely, Bimo or Suni people display or demonstrate to the audiences through ceremonies or stunts, and narrate the Bimo legends in history or inherit ethnic language and culture. In the past, Bimo and Suni people were mainly active in major religious rites such as religion sacrificial festivals, major sacrificial events and weddings and funerals, the time was mainly festivals and seasons and the space was mainly villages. And now the survival time, space, content and form all underwent changes. Taking Shilin Yi Autonomous County as an example, at 
present, the county is actively planning to develop the local $\mathrm{Yi}$ Bimo cultural garden and concentratively exhibit the history and status of Bimo culture and its role on Yi social development through material objects, pictures and sculptures. The display contents can include Bimo paintings, Bimo sacred books, Bimo legends and Bimo rap. In addition to Bimo cultural museum, the development of Bimo cultural tourism products should be paid attention to, as Bimo culture has strong national peculiarity and mystery. For tourists, Bimo culture can give them a sense of freshness and mystery, which can be recognized and accepted as an exotic culture and lays the foundation for the flourish of the traditional culture of the Yi nationality.

The tourism development of ethnic traditional culture needs to be recognized by the market, and the marketization process of Bimo culture requires ongoing cultural reproduction, which is similar to the pipeline operation mode of products, only by weeding through the old to create the new, will the consuming desires of different visitors towards national traditional culture be met, thus more effectively maximizing the market interests. In this regard, the traditional quintessence of Bimo culture needs to be extracted and purified, the new trends of the market need to be captured and new elements should be added constantly, so as to meet the tourists' curiosity about exotic cultures. Therefore, Bimo culture is extracted from the traditional Yi people's life and improved through processing and innovation to make it different from the traditional life pattern.

Bimo culture as "intangible cultural heritage". In the intangible cultural heritage list, there are a total of 47 national, provincial, municipal and county-level Bimo inheritors in Shilin County. Bimo culture has been transformed into the elite class version of intangible cultural heritage from the initial official version of feudal superstition, continued to bring forth the new through the old and finally been recognized by society. The construction of Bimo culture' intangible cultural heritage identity cannot be separated from the artificial depictions of official scholars and other social elite class, which made the culture move towards the cultural identity recognized by the society from the traditional mode, enabled the culture to be known and recognized by the public in a wider range and endowed it with the due cultural dignity and sense of honor. To some extent, this is the renaming and definition of Bimo culture and the reposition on the national culture made by the social elite class under the guidance of the social opinions in modern countries.

In the society of modern countries, Bimo culture has obtained double identities, one is the custom identity of the culture rooted in the inheritance and development of village culture as traditional culture, which has relative stability, national uniqueness and mystery; the other is the identity of the organic component of the intangible cultural heritage. The construction of the identities is a process in which the social elite class represented by official scholars refines, packages, improves and consciously sublates the traditional national culture, preserves the positive and efficient elements and gets rid of the components inconsistent with the contemporary social culture and adds artificially designed national characteristics into Bimo culture. This behavior can be deemed as a performance of cultural reproduction.

The reproduction behavior of Bimo culture refers to that the social elite class as the representative refines, improves and sublates the culture, strengthens the sense of national identity and the identity consciousness, and elevates Bimo culture from a tangible product to intangible ethnic values. Through the continuous strengthening of the ethnic identity of Bimo culture as the intangible culture heritage, the official has made the reproduction behavior from the original regional ethnic cultural behavior to the sense of national identity and the cultural behavior recognized by the whole social group.

\section{The interpretation of the reproduction phenomenon of Yi nationality Bimo culture}

Interpretation of the symbolization function of Bimo culture. The symbolization of Bimo culture is mainly embodied in two functions: one is acting as the symbol of cultural inheritance. Bimo culture is the ethnic culture of Yi nationality. In today's social environment, Bimo culture has been elevated and become one of the symbols of Yi culture. The symbolized Bimo culture extracted from Bimo culture represents the common national sentiments and spiritual beliefs of the Yi nationality, it is the soul of Yi culture and the symbol of cultural heritage, it elevated Bimo culture 
to one of the extensive and profound cultural representatives of Chinese nation, and its identity has become a symbolic product of the cultural symbols of the Chinese nation; the other is acting as the aesthetic symbol. The religious buddhist musical apparatus, clothing, painting, sacred classics, sculpture and paper cutting of Bimo and Suni have high aesthetic value. Taking the Bimo paintings as an example, the paintings were originally used to explain the contents of the scriptures or rituals, so as to achieve the purpose of ritual or language visualization. With the rapid development of the market economy, Bimo paintings have appeared in various occasions such as painting creation, museums and tourist commodities. The symbolization behavior of Bimo paintings cannot be separated from the social elite class's packaging and refining, which endowed the paintings with high aesthetic value and made them into aesthetic objects for people's appreciation.

The driving forces for cultural reproduction of Yi nationality Bimo culture. Firstly, the local elites constitute the key factor of the reproduction. Local elites mainly include those who take Bimo culture as the object of study and are involved in the studies of the cultural inheritors, the tangible data such as Bimo cultural relics and literature and the intangible data such as the spiritual connotations of $\mathrm{Bi}$ culture. As a hierarchy with social status and influence, local elites have a lot of social resources and official academic influence, their understanding and recognition of Bimo culture will act on local people through various channels, so that the latter will generate a sense of national identity and belonging. " In addition, local elites have been given the tasks of promoting distinctive local culture to the outside world and producing cultural products for local people, so as to make them satisfied with the local culture. It is precisely because of the tasks, the local elites get the power of discourse in the excavation and construction of regional culture"[4].

Secondly, the public constitute the basic factor of the reproduction. The general public mainly include local audiences and exotic tourists. "Yi nationality Bimo religion is the product of certain historical conditions. The religion takes natural worship, totem worship, spiritual beings worship, ghost worship and ancestor worship as the core contents and the sacred books held by Bimo as the carrier. The sacrificial ceremonies are presided over by Bimo and still in the stage of objects and images. The religion adjusts the relations between man and nature and between human and society in Yi society" [5]. Bimo culture is an organic component of the Yi nationality Bimo religion, so it has a favorable mass base and strong vitality. The local people are practitioners of the traditional Bimo culture and the external tourists add multivariant and fresh blood to traditional Bimo culture, so that the traditional religious beliefs are integrated with external culture and arts, which together promote the inheritance and reproduction of culture.

Thirdly, the government constitutes the promoting factor of the reproduction. The government departments of Shilin County joined the ranks of Bimo cultural reproduction. The development of cultural undertakings is one of the job contents of the local government. Since 2005, Shilin National Bureau of Religious Affairs has successively collected and sorted out a number of Bimo literatures, organized yearly Bimo training class and conducted Bimo qualification recognition and review. In addition, the Intangible Cultural Heritage Office of Shilin County actively organized the recognition work of Bimo intangible cultural heritage, and there are already dozens of Bimo intangible cultural heritage inheritors in the intangible cultural heritage list. Since the government departments of Shilin County included Bimo culture into the propaganda objects, the outside world has gotten a more profound understanding of the county's cultural resources, more social elites begin to focus on the development of the national traditional culture in the county and the public have deepened their understanding of this, which created advantageous chances for Bimo cultural reproduction in Shilin County.

The influence of cultural reproduction on traditional culture. The reproduction of $\mathrm{Yi}$ nationality Bimo culture is based on the ethnic traditional culture and is bound to exert a profound influence on the culture. The phenomenon of cultural reproduction is a combination of "modern" and "traditional", as well as a kind of "sublation" and "reconstruction" of the ethnic traditional culture. In the modern context, the social elite class represented by the official sublates the Yi nationality Bimo culture, endows it with the new social and cultural identity of intangible cultural heritage and makes it more widely recognized in the society. Nowadays, modern elements have 
been added into Bimo culture, epochal character has been given to the culture, and ceremonial performance appears, which makes the culture more attractive and appealing and thus can be better integrated into modern society. The reproduction is to refine, imitate, package and innovate the ethnic traditional culture, reconstruct the survival state of Bimo culture, and make the survival state effectively combine with the current social culture basis, "it is actually a kind of criticism and reconstruction and even the emergence of new tradition". When the rebuilt posture of traditional culture is repeated and reproduced in the future, the reconstructed "new tradition"will form the so-called "traditional" culture in the continuous historical accumulation [6].

\section{References}

[1]Xu Ming. Bimo Culturalism[J]. Journal of Southwest Institute for Nationalities(philosophy and social science edition), 1989, (3).

[2] Zhong Jingwen. Introduction to Folklore.[M]. Shanghai: Shanghai Literature and Art Publishing House, 1998:17.

[3] Gao Xuanyang. Bourdieu's Social Theory [M]. Shanghai: Tongji University Press, 2004.

[4] Qiu Yunsheng. Ethnic Identity and Ethnic Group Construction of Yunnan Qiubei Bo People (Bai Yi Branch) [D]. Yunnan Minzu University, 2011.

[5] Cai Hua, Giertiri, Gahashizhe, Zimowuguo. Investigation of Present Religious Situation of Yi Bimo [J]. Journal of Southwest University for Nationalities (humanistic and social science edition), 2005, (10).

[6] Wang Jin, Liao Ling. The Theory of Bimo Cultural Reproduction- the Application of Bourdieu's Theory in the Research of Bimo [J]. Social Sciences in Yunnan, 2010, (6) 